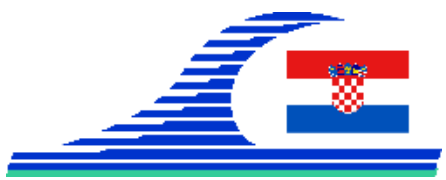

\title{
Integrated concentration statistics from river generated pollution in coastal zones
}

\author{
Morena GALESIC ${ }^{1}$, Roko ANDRICEVIC ${ }^{1}$, Vladimir DIVIC ${ }^{1}$
}

1. University of Split, Faculty of Civil Engineering, Architecture and Geodesy, Matice hrvatske 15, 21000 Split, Croatia.

mgalesic@gradst.hr ; rokoand@gradst.hr ; vdivic@gradst.hr

\begin{abstract}
:
River estuaries represent one of the most valuable and nevertheless most fragile ecosystems. By their own definition they act as an interactive border between river and sea, hence obtaining characteristics of both environments and yet unique ones such as brackish water or funnel shape. On the other hand, human impact is great at such coastal ecosystem due to multiple interests involved, ranging from agricultural via transportation to recreational activities. The river generated pollution is one of the most important threats to estuary ecosystem; hence this research investigates the potential of integrated concentration statistics as a measure of dilution and risk assessment. Previous work conducted includes the definition of pollution concentration moments and corresponding probability density functions. Hence, based on developed simple analytical solution for obtaining the moments, a more robust measure of dilution is introduced - expected mass fraction. The concept of expected mass fraction was previously used by several authors concerning the dilution processes in environmental flows. Being applied for an estuarine system for the first time, such measure is defined by spatial integration of point statistics over available volume. The result is an estimate of pollutant mass existing at some downstream distance which has the concentration above defined limit value. That kind of information gives potentially useful loading estimate when doing pollution risk assessment of the estuary ecosystem.
\end{abstract}

Keywords: Estuaries, River generated pollution, Pollution concentration moments, Probability density function (PDF), Expected mass fraction (EMF), Pollution loading estimate.

\section{Introduction}

Estuaries are complex ecosystems, however, they tend to be presented with some rather simple principles as described in research by previous authors (SAVENIJE 2005; CAI \& SAVENIJE, 2013), which comes useful regarding the fact that most of estuaries are ungauged (SAVENIJE, 2015). Within lot of studies and research being conducted in estuaries and coastal zones (SARAIVA et al., 2007; PINTO et al., 2013; WANG et al., 
Mediterranean rocky coasts:

Features, processes, evolution and problems

2017; OGUNOLA et al., 2017), we focus on the problem of nutrient loadings (e.g. nitrogen, phosphorous) and their transport process which may be considered as conservative one. Nutrient concentration statistics represent important data when analysing estuarine water body and it is also followed by European Commission directives (OJEC, 2000) and national regulations for water quality and bathing water quality (OJEU, 2006). When analysing the risk and the level of pollutant concentration dilution in environmental flows, due to its random nature, one is encouraged to use the stochastic approach and work with concentration statistics. Pollutant concentration data are statistical moments and probability density functions (PDF) which are defined in point. The above mentioned directives suggest the classical approach in defining the risk by using the point PDFs (SULLIVAN, 1997; GANOULIS 2009), which usually faces the challenge of dependency to a vast number of realizations or measurements. Such problem raises a necessity for a different measure of dilution. This research presents a follow up for the project and research described in (GALESIC et al., 2016) where the analytical model for calculating pollution concentration statistics at an arbitrary point of an estuary was developed. The concept of expected mass fraction (EMF) is introduced into an estuarine system to meet the need for a more robust representation of dilution process. Such concept was previously engaged in research of atmospheric and groundwater transport processes (HEAGY \& SULLIVAN, 1995; ANDRICEVIC et al., 2012) and here it is applied by spatial integration of concentration statistics.

\section{Methodology}

The problem of mixing in the near field zone of a river dominated stratified estuary (depth integrated - 2D scheme) where steady and continuous river plume is entering coastal sea is observed. Such phenomenon is characterized by a combination of small scale turbulent diffusion and a larger scale variation of the advective mean velocities (FISCHER et al., 1979). For conservative pollutant concentration, the fundamental advection diffusion equation is given:

$\frac{\partial c(\mathbf{x}, t)}{\partial t}+\nabla \cdot[v(\mathbf{x}, t) c(\mathbf{x}, t)]=e_{m} \nabla^{2} c(\mathbf{x}, t)$

where $c(\boldsymbol{x}, t)$ is the scalar concentration, $\boldsymbol{v}(\boldsymbol{x}, t)$ is the flow velocity located by vector $\boldsymbol{x}$ at time $t$ and $e_{m}$ is the coefficient of molecular diffusion. After multiple averaging and an implementation of a near field zone approximation, a recursive solution for obtaining absolute statistic moments $\left(m_{n+1}\right)$ is obtained: 


$$
m_{n+1}(x)=C_{o}^{n} \bar{c}(x)+\frac{k \alpha}{U} e^{-\frac{k \alpha}{U} x} \int_{0}^{x}\left[2 m_{n}(\eta) \overline{c_{t}}-m_{n-1}(\eta) \bar{c}_{t}^{2}-C_{o}^{n} \bar{c}(\eta)\right] e^{\frac{k \alpha}{U} \eta} d \eta
$$

where $C_{0}$ is the source concentration, $k=n(n+1), \alpha=e_{m} / \lambda \wedge 2$, and $c_{t}$ is the background threshold concentration, and $U$ is the mean velocity vector $\left(v(x, t)=U\left[U_{x}, 0,0\right]\right)$. The parameter $\lambda$ defines the scale of concentration gradient, $\nabla c=\left(c-c_{t}\right) / \lambda$.

Furthermore, the PDFs can be reconstructed by moment inversion and one may obtain the probabilities of exceeding the limit concentration at a chosen point as shown in results section (Figure 2). But the crucial idea here is to upgrade this measure of dilution by applying the expected mass fraction:

$$
f(c ; t)=\frac{1}{M} \int_{V} c p(c ; x ; t) d v
$$

where $V$ represents the available volume considered to have conserved and constant mass $M$ due to continuous steady state being observed. This way EMF represents an integrated measure of concentration statistics and it is obtained by numerical integration of previously calculated PDFs (Figure 1):

$$
f(i)=\frac{1}{M} \sum_{c} \sum_{y} c p\left(c, x_{i}, y\right) d c
$$

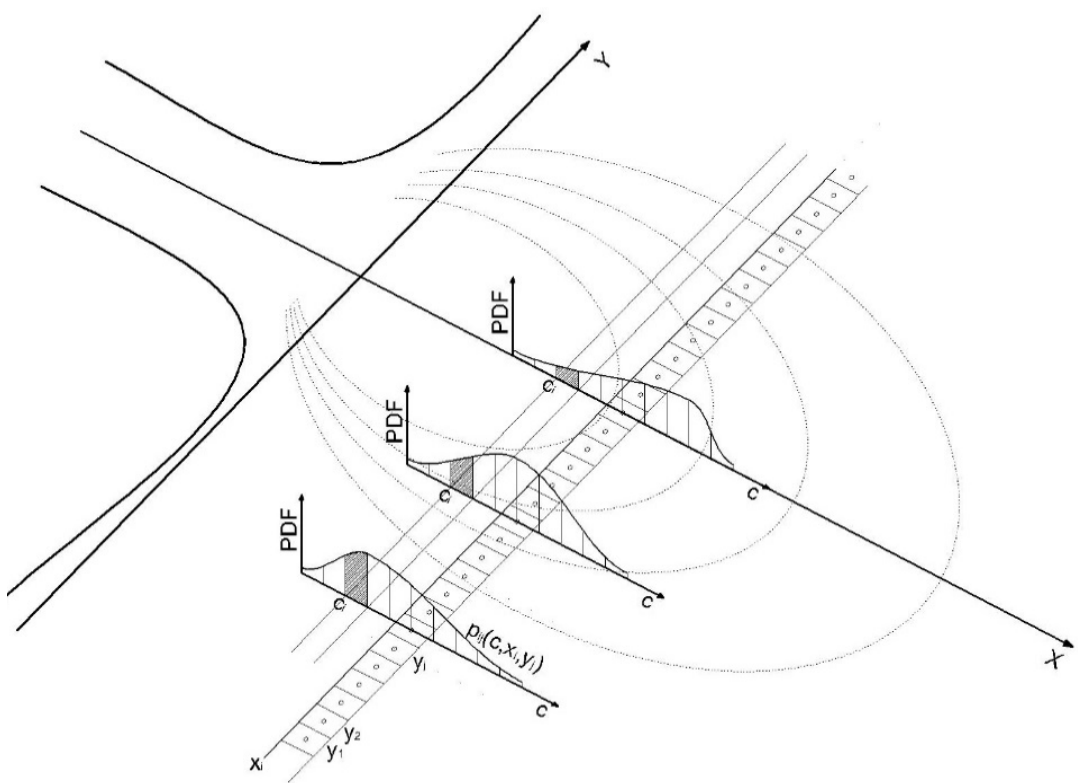

Figure 1 - Schematic representation of spatial integration of pollution concentration PDFs for chose downstream slice.

If one is to integrate the EMF for limit value of concentration $-c^{*}$ : 
Mediterranean rocky coasts:

Features, processes, evolution and problems

$F\left(c^{*}\right)=\int_{c^{*}}^{\infty} f(c ; t) d c$

The obtained cumulative distribution function $-\mathrm{F}\left(\mathrm{c}^{*}\right)$ represents direct, more intuitive application of an EMF by defining the fraction of mass consisting of concentrations equal or higher than chosen limit value.

\section{Results}

The developed analytical solution for obtaining the concentration moments and point PDFs is visualised on a pilot area of Žrnovnica estuary near the city of Split, where at given arbitrary points, the probabilities of exceeding the limit concentration (of total nitrogen in this case) are shown. The moment inversion was conducted by fitting the moments obtained by recursive expression (2) to a beta PDF which was previously tested as a good representation of dilution processes in environmental flows (CHATWIN et al., 1995). By implementing the (4) continuously along the downstream slices the corresponding EMFs are obtained and shown in Figure 3. One may notice how initially there is the mass of pollutant with higher concentration, but it is systematically shifted to lower values of concentration in further sections.

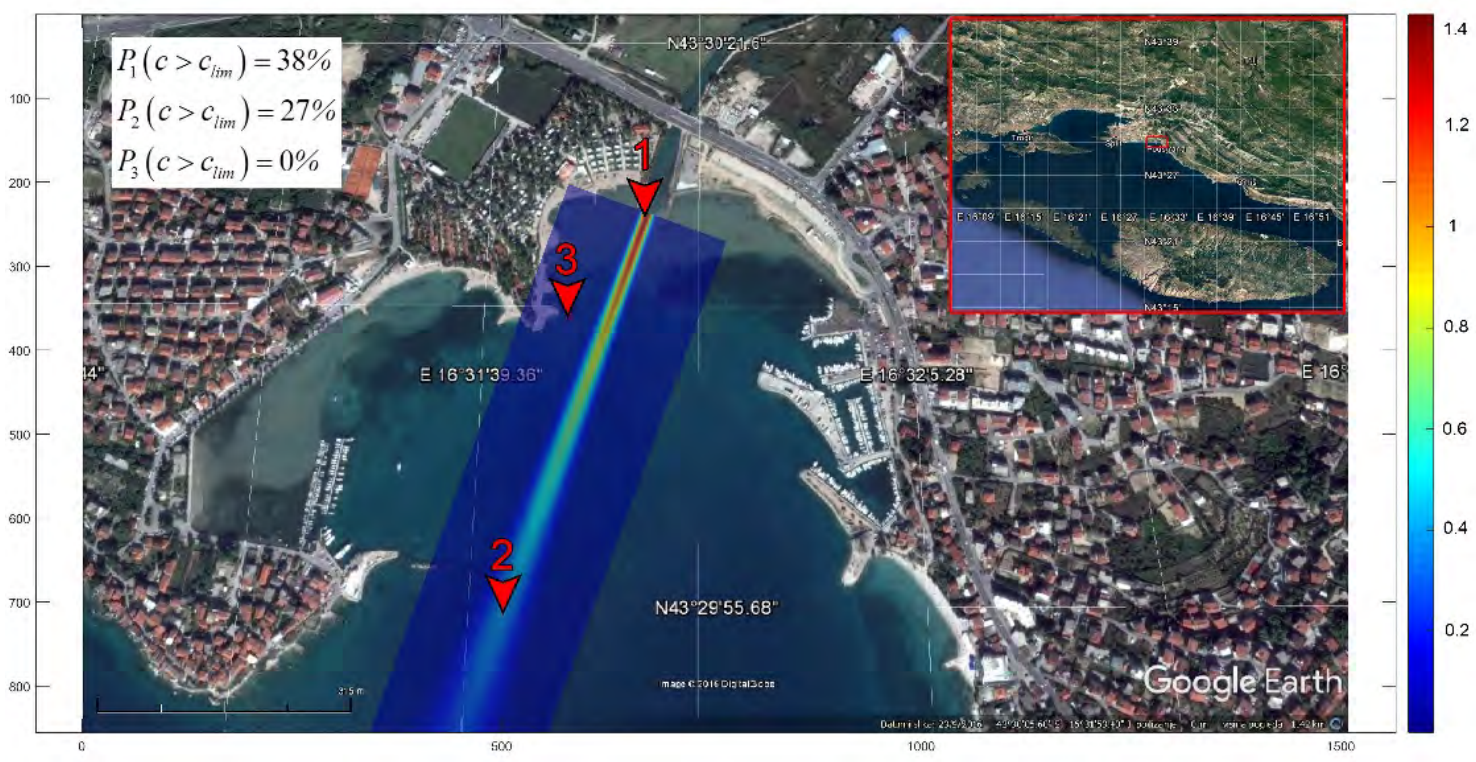

Figure 2. Žrnovnica estuary map with mean concentration results and probabilities of exceeding the limit concentration at chosen points (background map is courtesy of Google Earth). 


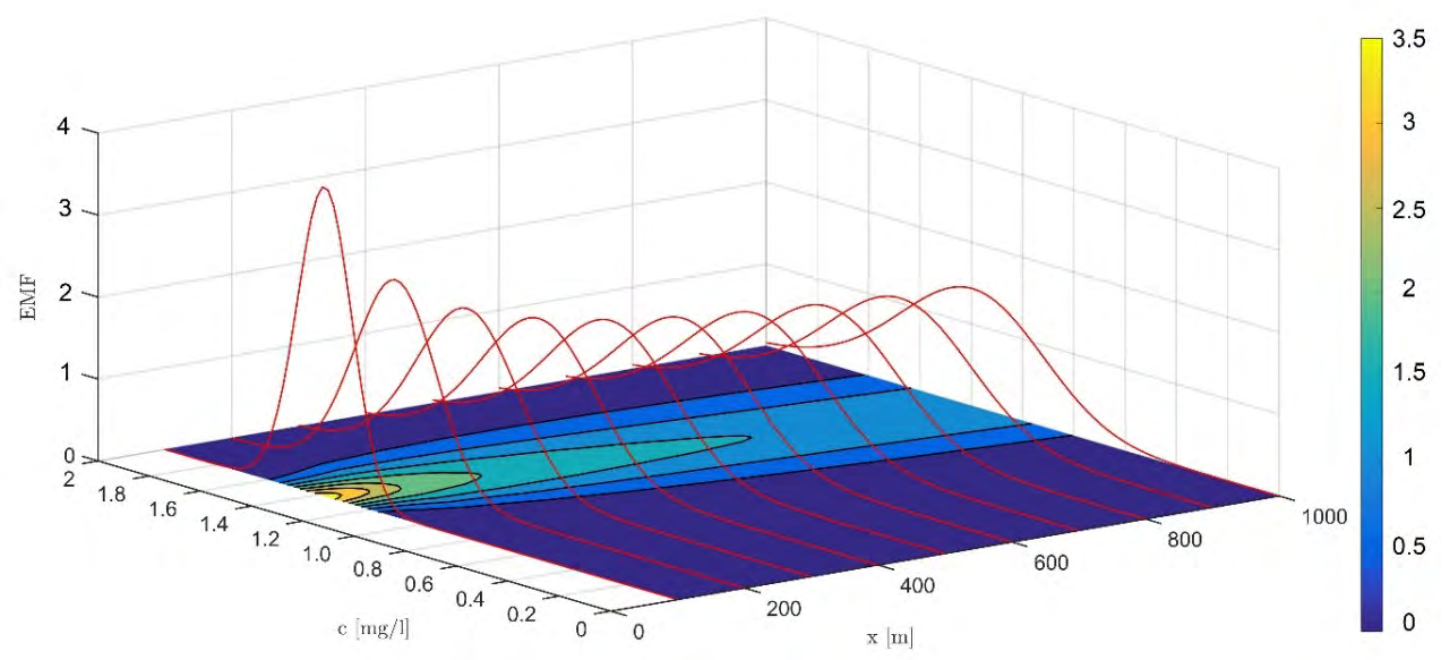

Figure 3. Obtained EMFs at different distances from the river mouth.

\section{Conclusions}

Such integration of point PDF overall available space (in this case the perpendicular slice of the downstream estuary) to obtain an EMF gives new measure of dilution - the fraction of mass that exceeds the limit concentration at chosen distance from the pollution source (i.e. river mouth). Observed mass reduction is certainly expected, however, the prediction of distance from the river mouth at which there is no more mass of some critical concentration shows worthy potential in risk assessment. It gives more robust assessment by defining the loading to the aquatic system as opposed to single point data which is hardly representative for a water body. The ongoing and future research include further development of integrated concentration statistics to make it less dependent of the choice of point pdf and an introduction of spatially integrated concentration moments.

\section{Acknowledgment}

We acknowledge the support of student research grant co-funded by European Social Fund for the Project HR.3.2.01-0262, Risk assessment of the Pollution caused by rivers and discharges in coastal area (project CPoRT- Coastal Pollution Risk Tool).

\section{References}

ANDRICEVIC R., SRZIC V., GOTOVAC H. (2012). Risk characterization for toxic chemicals transported in aquifers. Advances in Water Resources, 36, pp. 86-97. doi.org/10.1016/j.advwatres.2011.04.009

CAI H., SAVENIJE H. H. G. (2013). Asymptotic behavior of tidal damping in alluvial estuaries. Journal of Geophysical Research: Oceans, 118(11), pp. 6107-6122. 
Mediterranean rocky coasts:

Features, processes, evolution and problems

CHATWIN P. C., LEWIS D. M., SULLIVAN P. J. (1995). Turbulent dispersion and the beta distribution. Environmetrics, 6(4), pp.395-402. doi.org/10.1002/env.3170060408 EJEU. (2006). Directive 2006/7/EC of the European parliament and of the council of 15 February 2006, concerning the management of bathing water quality and repealing. Directive 76/160/EEC, Official Journal of the European Union, L64/37-L64/51.

OJEC. (2000). Directive 2000/60/EC of the European parliament and of the council of 23 october 2000 establishing a framework for Community action in the field of water policy. Official Journal of the European Communities, L327/1-L327/72.

FISCHER H. B., LIST E. J., KOH C. Y., IMBERGER J., BROOKS N. H. (1979). Mixing in inland and coastal waters, Academic Press.

GALESIC M., ANDRICEVIC R., GOTOVAC H., SRZIC V. (2016). Concentration statistics of solute transport for the near field zone of an estuary. Advances in Water Resources, 94, pp. 424-440. doi.org/10.1016/j.advwatres.2016.06.009

GANOULIS J., 2009. Risk analysis of water pollution, Wiley-VCH Verlag GmbH \& Co. KGaA. Weinheim, Germany. doi: 10.1002/9783527626663

HEAGY W. K., SULLIVAN P. J. (1995). Cloud concentration statistics and dosage. Mathematical and Computer Modelling, 21(9), pp. 61-65. doi.org/10.1016/0895-7177(95)00053-5 OGUNOLA O. S., ONADA O. A., FALAYE, A. E. (2017). Ecological risk evaluation of biological and geochemical trace metals in Okrika estuary. International Journal of Environmental Research, 11(2), pp. 149-173. doi.org/10.1007/s41742-017-0016-4 PINTO R., DE JONGE V. N., NETO J. M., DOMINGOS T., MARQUES J. C, PATRICIO J. (2013). Towards a DPSIR driven integration of ecological value, water uses and ecosystem services for estuarine systems. Ocean and Coastal Management, 72, pp. 64-79. doi.org/10.1016/j.ocecoaman.2011.06.016

SARAIVA S., PINA P., MARTINS F., SANTOS M., BRAUNSCHWEIG F., NEVES R. (2007). Modelling the influence of nutrient loads on Portuguese estuaries. Hydrobiologia, 587(1), pp. 5-18. doi.org/10.1007/s10750-007-0675-9

SAVENIJE H. H. G. (2015). Prediction in ungauged estuaries: An integrated theory. Water Resources Research, 51(4), pp. 2464-2476. doi: 10.1002/2015WR016936

SAVENIJE H. H. G. (2005). Salinity and tides in alluvial estuaries, Amsterdam: Elsevier.

SULLIVAN P. J. (1997). Modelling the hazards posed by sudden release of a quantity of contaminants. Environmental Modelling and Software, 12 (1), pp. 59-65. doi.org/10.1016/S1364-8152(96)00027-8

WANG Y., CASTELAO R. M., DI IORIO D. (2017). Salinity variability and water exchange in interconnected estuaries. Estuaries and Coasts, 40(4), pp. 917-929. doi.org/10.1007/s12237-016-0195-9 